This item was submitted to Loughborough's Institutional Repository (https://dspace.lboro.ac.uk/) by the author and is made available under the following Creative Commons Licence conditions.

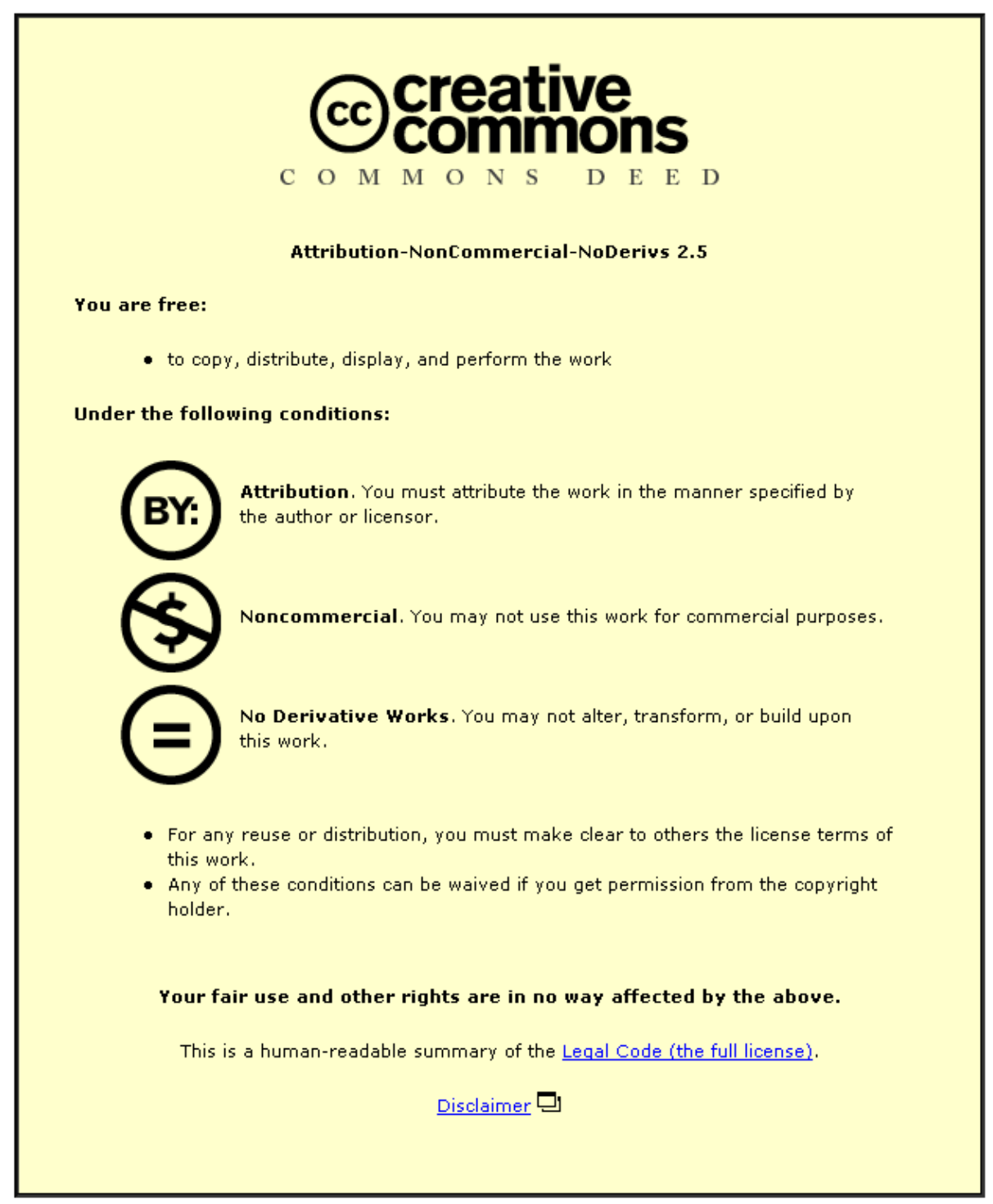

For the full text of this licence, please go to: http://creativecommons.org/licenses/by-nc-nd/2.5/ 
Transport

Volume 165 Issue TR3

UK rail transport: a review of demand and supply

Ison, Frost and Watson
Proceedings of the Institution of Civil Engineers

Transport 165 August 2012 Issue TR3

Pages 225-234 http://dx.doi.org/10.1680/tran.10.00028

Paper 1000028

Received 18/04/2010

Published online 18/11/2011

Keywords: management/railway systems

ICE Publishing: All rights reserved

\section{UK rail transport: a review of demand and supply}

1 Stephen Ison MA, PhD, CMILT

Professor of transport policy, Transport Studies Group, Department of Civil and Building Engineering, Loughborough University, UK
2 Matthew Frost BEng (Hons) Dis, PhD, PgcHE, MPWI Senior Lecturer in geotechnical engineering, Department of Civil and Building Engineering, Loughborough University, UK

3 Robert Watson MPhil, PhD, CMILT, MCIM Associate, Steer Davies Gleave, London, UK

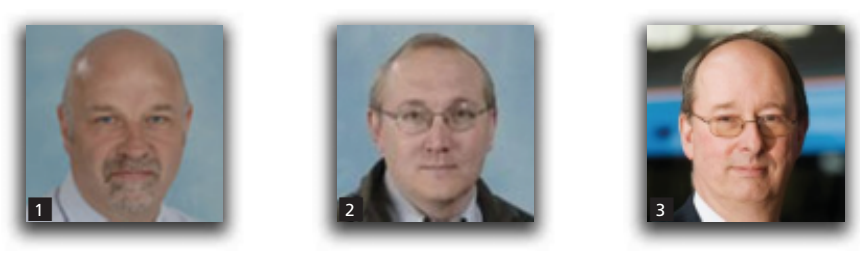

Over recent years the UK railway industry has seen unprecedented growth in the number of passengers and the amount of freight carried. Expansion in network capacity, however, has not kept pace with this growth. This has led to significant overcrowding and little or no capacity left to run more trains within existing stock or track provision. The UK government however has stated that as part of achieving 'best value' it wants to further increase rail traffic, and has recently set out a strategy to optimise this. This paper reviews the issues associated with the growth in passengers, the demand placed on the network and the policy developed to accommodate and manage it. It identifies the capacity constraints and options identified for capacity enhancement. The paper concludes that while privatisation has made coherent decision-making difficult there is significant experience to be gained in the development of policy and route utilisation strategies.

\section{Introduction}

The rail industry is seen as a vital public service, which costs the UK taxpayer and for which the UK government, via its Department for Transport (DfT), has set the following aim, namely to

secure the best value for passengers, freight users and taxpayers from a fixed transport budget, and to ensure that the transport needs of different users and of different regions and communities are met in the most efficient way possible. (DfT, 2004)

Over recent years the privatised UK railway has been successful in increasing passenger kilometres and freight tonne kilometres moved with growth in the number of trains that run and the number of passengers carried. The government has also stated that as part of achieving best value it wants to further increase volumes of passengers and freight using the railways.

The rail industry however has suffered, according to the DfT, from 'historic under investment' (DfT, 2004), which has led to the capacity available on the current network being reduced over the long term and this situation has been made worse by the pressure on capacity and the way in which the UK rail industry is structured (DfT, 2004). This, in turn, has led to significant overcrowding on trains in some areas, and in others little or no capacity left to run more trains within exiting stock or track capacity provision.
The present study aimed to review the issues associated with the growth in passengers and freight and the transport demand placed on the UK rail network and the policy developed to accommodate or manage it. The paper is divided into three sections covering policy, demand and supply. The section on transport and rail policy explains the government's policy and objectives for the railway. It is followed by railway transport demand and demand management, detailing how rail transport demand has grown and its potential for growth if capacity is available and, if not, for managing it. The next section provides an overview of railway capacity supply and its constraints and options are identified for enhancement to help meet the demand. Finally some conclusions are presented.

\section{UK government policy and objectives for the railway}

The UK government has set a number of objectives for the UK rail industry to achieve (DfT, 2009a).

(a) Ensure delivery of improved operational and financial performance, and safety.

(b) Secure appropriate rail passenger services at an acceptable price through effective specification and procurement.

(c) Develop and deliver a robust, affordable and sustainable strategy for the development of the railway that supports wider transport objectives. 
(d) Ensure the cost-effective and timely delivery of major rail projects.

Of particular relevance is the requirement to develop the railway to support wider transport objectives. To deliver this, more passengers and freight are required to travel by rail and this must happen in a more sustainable way. More recently the government has stated that it wants the railway in the long term, to (DfT, 2007b)

(a) deal with a doubling of passenger and freight traffic

(b) be safer and more reliable and efficient

(c) cater for a more diverse, demanding and affluent population

(d) reduce its carbon footprint and improve its environmental performance.

For the rail sector to deliver this increased demand and to play its part in the sustainability agenda it has to be organised in an efficient, cost-effective and appropriate manner. The fragmentary format of UK rail privatisation in the 1990s broke up the single entity of government-owned British Rail to create an infrastructure owner-operator, and a number of separate associated infrastructure maintenance and consultancy companies (separating both maintenance and renewals, for track, signals, and structures), franchised passenger operators (who leased trains from rolling stock companies) but owned rights to run trains on certain routes, and 'open access' freight operators. A track authority was established, namely Railtrack, a company that owned and managed the rail infrastructure, comprising the track, signalling and stations. Railtrack was also responsible for investing in new and maintaining existing infrastructure. The numerous firms created were sold to the private sector separately with their own income streams (DfT, 2004).

This created a system with little centralised control, all ruled by contracts, but this structure was devised assuming low, if any, rail transport growth and reducing government subsidy. Where growth was forecast the privatised infrastructure operator then failed to deliver effective network enhancement; in addition inadequate control of infrastructure maintenance led indirectly to significant cost escalation and rail accidents.

Public sector subsidy rose dramatically following privatisation, increasing from $£ 1.8$ billion in $1997 / 98$ to $£ 3.8$ billion in 2004 , with similar levels of investment from the private sector. This was partly the result of operating more services and undertaking infrastructure work, but it was also due to inefficiencies and consequent rising costs. One example of the rise in expenditure on infrastructure was that involving Railtrack following the Hatfield accident.

Overall there was seen to be a lack of leadership and integrated planning, which resulted in a lack of strategic thinking across the railway system. The government then created a Strategic Rail Authority (SRA) in 1999 to look at how the network should be developed and managed, but a perceived lack of visible progress over several years led to further reorganisation. The UK government published The Future of Rail in which it spelt out a blueprint for the railways (DfT, 2004).

(a) The government would take charge of railway strategy, including the level of expenditure (previously held with the SRA), the main aim being to protect the interest of both the taxpayers and the fare payers.

(b) Network Rail (the new infrastructure owner) (unlike Railtrack) would be given fuller responsibility for the operation and performance of the rail network. The reason for this was that with one organisation in charge then Network Rail's role would be strengthened in terms of planning and setting timetables hence being responsible and accountable for performance.

(c) That track authority and train companies must work more closely together, to improve efficiency.

(d) A better deal for freight, enabling the industry and its customers to invest for the long term.

The relationship between the government and the rail sector involves the organisations and responsibilities listed here.

(a) The government has control over strategy.

(b) The government specifies what Network Rail should deliver in terms of infrastructure outputs, these being priced via a high-level output specification (HLOS), and a statement of funds available (SOFA).

(c) An Office of the Rail Regulator (ORR) makes sure that the government pays the correct price for what it is buying.

(d) Operational leadership is provided by Network Rail.

(e) Train companies concentrate on train operation, customer service and marketing, with government setting service priorities.

The government now takes responsibility for

(a) the overall size and shape of the network

(b) the key timetable outputs

(c) policy on regulated fares

(d) minimum performance targets

(e) enhancement priorities

$(f)$ policy on information provision and accessibility.

Network Rail and the train companies have responsibility for

(a) drawing up route utilisation strategies that make best use of the network's capacity

(b) devising efficient and clear timetables based on those route strategies

(c) directing network operations

(d) improving the operational performance of the network

(e) devising and delivering infrastructure maintenance and renewals, and enhancements to the network as appropriate 
UK rail transport: a review of demand

and supply

Ison, Frost and Watson
( $f$ ) accounting publicly for performance.

In addition to addressing the increase in costs since privatisation the issues of performance and safety are seen as important objectives which impact on the demand for rail services. In terms of performance, improvements in the quality of service are being sought across a number of areas including

(a) improved punctuality and reliability

(b) better cleanliness and quality of trains

(c) improved journey times

(d) better personal security

(e) good customer service

$(f)$ accurate and timely information

(g) trains not being overcrowded.

In terms of all this the government on behalf of the taxpayer is keen to see 'value for money' and thus cost-effectiveness is seen as most important (DfT, 2004). The government looks for 'best value' for its expenditure on rail in terms of maximising the benefits derived from the investment (capital) and subsidy (operating cost) funding it provides. Benefits include faster journey times, reduced crowding, more punctual trains, reduced social exclusion, environmental and safety benefits through diverting journeys from road to rail; future expenditure is subject to an appraisal method that allows schemes to be ranked (see The NATA Refresh: Reviewing the New Approach to Appraisal (DfT, 2007a) and NATA Refresh: Appraisal for a Sustainable Transport System (DfT, 2009b)). Recently, the government declared its intention to 'rebalance' the contribution of taxpayer and fare payer in funding the rail network (House of Commons Public Accounts Committee, 2009) by requiring franchisees to increase ticket prices and reduce the amount of subsidy required from the government.

\section{Growing demand}

Rail currently accounts for 7 and $8 \%$ of total UK passenger and freight movements, respectively, and without a major increase in capacity, this may not result in a further increase (DfT, 2008). However, over recent years there has been an unprecedented increase in passenger travel (Figure 1) and an increase of 6 billion tonne kilometres of freight transported by rail over the 10 -year period. Overall, in Britain the railway now carries more passengers and freight than it did 50 years ago on a network some $30 \%$ of the size due to closures in the 1960s. So the railway is seen as a contributor to economic growth, having a role to play in managing road congestion, as well as contributing to the combating of climate change.

This growth in demand since privatisation has manifested itself on the network in the following ways (DfT, 2007b).

(a) The increase in the number of train services has meant there is less room for manoeuvre in terms of capacity to absorb the impact of system failures. As such, the system takes more time to get back to normal after disruption caused by infrastructure failures or train failures.

(b) Passenger growth has resulted in timetable issues and performance problems as a result of increased station dwell times (the time spent by trains for passengers getting on and off trains at stations).

(c) The greater intensity of train services has emphasised the fact that the network infrastructure is fragile. Long-term deterioration of the infrastructure, in particular structures (bridges, embankments and tunnels), means that there is a substantial backlog of maintenance and renewal to be undertaken. This has led to temporary speed restrictions being imposed in some places which has clearly reduced performance levels and leads to a high level of infrastructure failure.

\subsection{Influences on the recent increases in rail transport demand}

As stated above, when the rail industry was privatised it was without any particular expectation that passenger and/or freight volumes would grow considerably. However, as explained, this

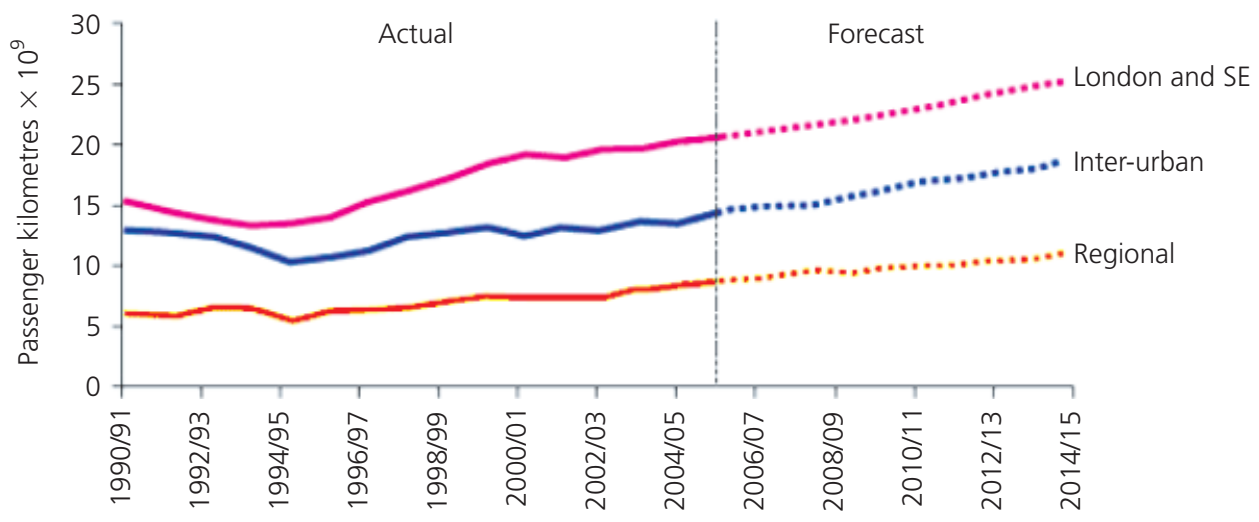

Figure 1. Forecast growth in UK passenger rail kilometres (DfT,

2007b). Crown copyright 
has not been the case; the factors leading to an increase in rail travel and usage are explained in the following subsections.

\subsubsection{Growth in GDP}

Transport is a derived demand and therefore it is to be expected that a growing economy will lead to growth in demand for rail services. The railway has therefore benefited, until recently, from a period of sustained economic growth. Growth in passenger and freight kilometres has outstripped growth in GDP, so other factors have also been at play (DfT, 2007b).

\subsubsection{Road congestion}

There is little doubt that road congestion has now reached levels where UK road journey times are increasing to the extent that some travellers (and freight operators) are moving from road to rail purely as a result of the changes in relative journey time (Goodwin, 2004).

\subsubsection{Greater frequency, new trains and new operators}

Although average UK rail journey times have not generally been improving, the number of train miles has increased significantly. Whereas for freight operators this increase relates directly to new business won, for passenger operators new services and increased frequencies have been introduced to win new passengers. The net effect of these additional services has been positive in terms of growth of demand, but it has had a negative effect too - growing congestion on the rail network.

Substantial numbers of newly built trains have been introduced over the past 10 years. As well as providing additional capacity these new trains have, on the whole, provided a better environment for passengers. On the freight side, a significant number of new locomotives and wagons have been obtained to cope with growing demand and to enable more efficient operation. New operators with new ideas have introduced 'open access' services. The effect on passenger services has not been marked, however a number of new freight operators now challenge the dominant operator (ORR, 2009).

\subsubsection{Pricing}

Freight moves by rail at a lower rate per tonne-km (after inflation) than a decade ago as a result of lower margins (a result of competition) and more efficient operations, and this has aided growth.

Passenger demand is more complex. Key fares (season tickets and standard class off-peak returns) are regulated by government. For a number of years these tickets were set to increase at retail prices index (RPI) $-1 \%$; that is, these fares went down relative to retail prices generally. More recently, however, the government has reversed this policy, seeking to fund the railways more from fares than from taxes, and these tickets now increase at RPI $+1 \%$. Following the government's spending review in October 2010, the cap will be increased on regulated fares to an average annual increase of RPI $+3 \%$ for a 3 -year period, from
January 2012 (DfT, 2010a). As such, fares are likely to increase by $10 \%$ over the next 4 years. This is seen to be a means by which the government can provide capacity improvements that are regarded as a priority in order to address overcrowding and improve the level of service, while not increasing the overall subsidy to the railway. Other fares are 'unregulated', leaving the train operators freedom in terms of what they charge. They use 'yield management' to maximise their revenue within the constraints set by the regulated fares - offering a range of 'walk on' tickets and advance purchase tickets (requiring travel on specific trains) at different prices and in different quantities, seeking to charge the most they can to each passenger, particularly when trains are busy, while encouraging new passengers through low fares when seats would otherwise be empty (DfT, 2007b; ORR, 2009). There has been a rise in non-regulated fares, in real as well as money terms.

Overall then, in the early years of privatisation, pricing had a positive impact on demand. More recently with RPI + pricing of regulated fares and franchise specifications from government that require RPI + pricing for unregulated fares (overall) we are now in a situation where pricing will suppress demand to some extent.

\subsubsection{Reliability: cancellations and punctuality}

Reliability has an important impact on overall demand; after privatisation between 2000 and 2002 there was a significant drop in reliability and this interrupted growth. However, since then there has been a sustained improvement in performance. The standard measure used by the rail industry of reliability is public performance measure (PPM), combining cancellations into a punctuality measure, with trains over $10 \mathrm{~min}$ late for longdistance operators and $5 \mathrm{~min}$ late for local and suburban operators 'failing' the measure. From a figure of $79 \cdot 2 \%$ in $2002-2003$, by 2009 PPM was $90.7 \%$ (ORR, 2009). This has helped demand continue to grow over the past few years.

\subsubsection{Crowding}

Of course, increased crowding on trains has a negative impact on demand. This has traditionally been a problem in peak hours into and out of London, but growing demand has led to crowding in other conurbations and also on long-distance trains - particularly on Friday evenings and Sunday afternoons, but on some routes (in particular Cross Country and East Coast) some trains are crowded every day of the week. Additional services and new higher capacity trains have helped, but crowding has constrained growth to some extent.

\subsection{Prospects for future growth in demand}

Overall it can be seen from the above that a number of factors have been at play in delivering increased demand for rail transport - some positive, some negative. However, to assess future growth in rail demand, in March 2009 Network Rail published Network RUS: Scenarios and Long Distance Forecasts, a Draft for Consultation (Network Rail, 2009a). The document 
considers the following four scenarios which could impact on future rail growth.

(a) Global responsibility: the UK as a global player with a sustainable agenda.

(b) Local awareness: a more decentralised economy with a sustainable agenda.

(c) Continued profligacy: the UK as a global economy with unabated consumption.

(d) Insularity: a more decentralised economy with unabated consumption.

It stated that factors which impact on these various scenarios include economic development, the degree of trade between the UK and other countries, social trends, energy prices and the extent to which a particular mode recovers its external costs. Overall therefore there are two key factors, namely economic growth and sustainability linked to energy and carbon use and overall environmental impact.

Taking account of the fact that long-term forecasts are by no means certain, the passenger rates of growth forecast vary from $28 \%$ in 30 years in the London to Southampton corridor in the local awareness scenarios to $95 \%$ in 30 years in the Cross Country corridor in the global responsibility scenarios. With respect to freight, there are variations between the different scenarios. Factors impacting on long-term demand include the issue of sustainability and the effect that this has on the amount of coal transported and the positive impact on rail freight in general. According to the document the carriage of coal is likely to be the greatest in the continued profligacy scenario and lowest in local awareness where it is forecast that there will be a $70 \%$ decrease. As stated, forecasting rail demand is not an exact science, as it is a derived demand and therefore dependent upon the level of economic activity. Figure 1 shows the forecast growth to 2015 .

\section{Delivering growth and rail capacity supply}

A major issue faced by the rail sector is the fact that capacity has failed to keep pace with the growth in demand, even given rising investment described above. However, most of this investment has not been in enhancing capacity, with most of it being renewal of existing assets.

\subsection{Measuring capacity}

The capacity of the railway can be defined broadly in two ways.

(a) The maximum number and size of trains that can be planned into a timetable (allowing for station stops, conflicting movements at junctions; mixing of fast, stopping and freight services; maintenance and commercial requirements), while operating reliably allowing for daily events and recovery following those events to provide adequate performance. (b) The number of seats or train paths available to meet passenger or freight demand.

The above is summarised in terms of trains per hour (tph) (or passengers per hour) and can be further summarised into two broad components.

(a) Physical capacity (i.e. the number and size of trains that can be physically run).

(b) Operational capacity to provide the robustness and the service required within the operational constraints or commercial constraints (i.e. the working timetable).

However, in many ways both of the above are interlinked as the physical capacity of the infrastructure (i.e. the track, stations, bridges and tunnels) is affected by the operational control systems in place and what was deemed to be suitable at the time they were built or modified as the network has developed (signalling and predicted train service patterns and demand). The physical capacity in turn will have influenced the way those operational systems may have been developed over time and the size and speed of trains that can be run. For example, service patterns of mixing of long-distance expresses, stopping commuter trains and freight trains will influence how much capacity is available within a given amount of track space, and platform and stock availability control the number and size of trains based in part on the original designed service.

In many areas of the UK the demand for rail travel is well below the maximum capacity available or provided. However, on many parts of the network due to the growth in demand (discussed in earlier sections), this is not the case and the demand for train travel outstrips the capacity at key times of the day. Consequently, Network Rail has investigated current rail capacity utilisation and produced capacity utilisation maps and indices as part of their route utilisation strategy development to indentify key track capacity constraints and locations for the whole network (Figure 2).

The physical capacity of the rail network can be roughly broken down into eight categories

(a) track capacity

(b) structure gauge

(c) junction capacity

(d) signalling

(e) station capacity

$(f)$ terminal capacity

(g) train capacity and speed/acceleration

(h) track availability.

However, some of the above factors are more critical than others. For passengers on overcrowded sections of the network there are simply not enough carriages; however, that may be a function of platform and station length. As well as physical constraints on train length, franchised operators may have limited financial 


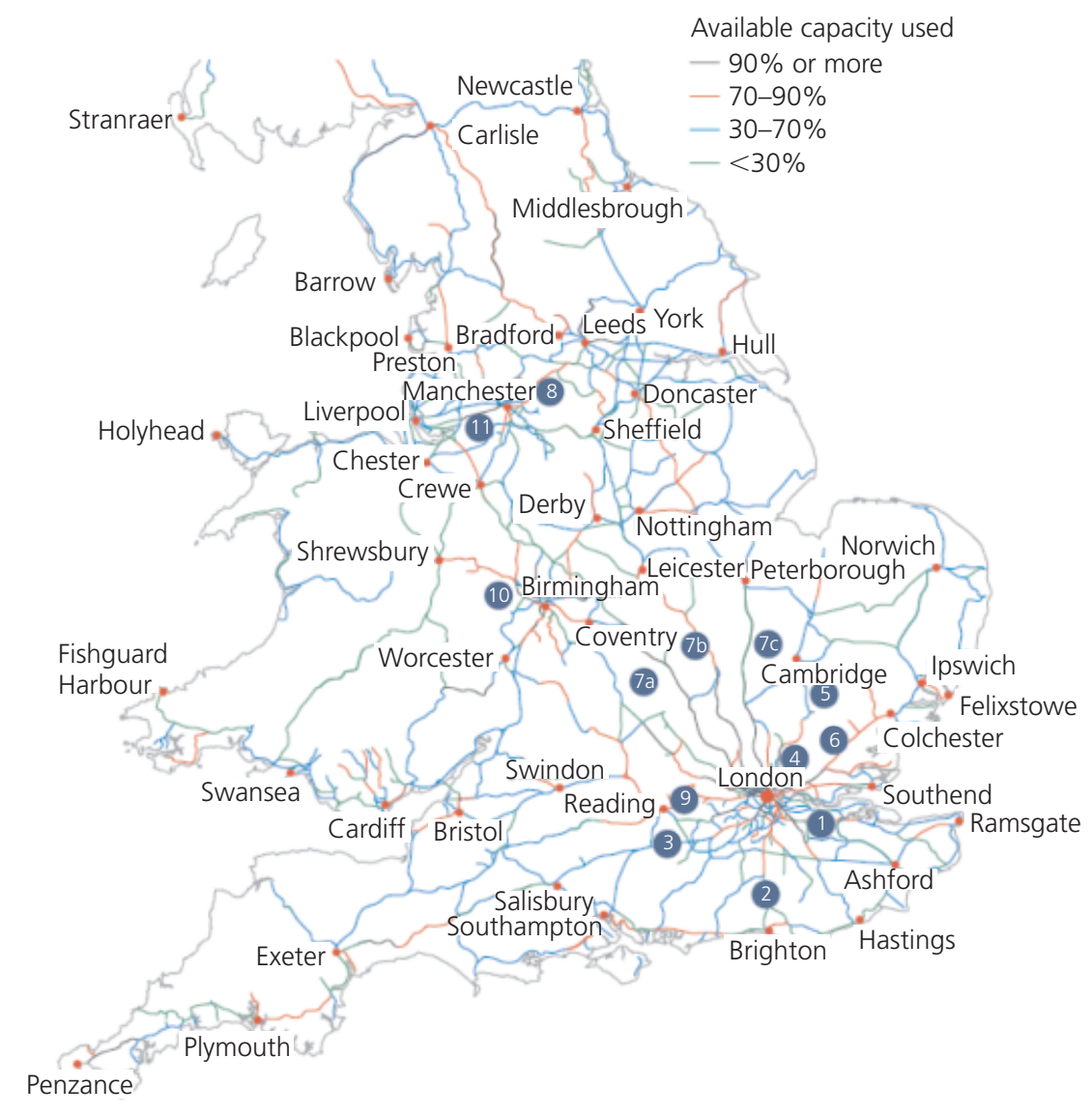

Significant capacity constraints

- London-Dartford/Orpington

2. Brighton Main Line

3) South West Main Line

(4) London-Bishops Stortford

(5) Stansted, Cambridge and Ely

6 Great Eastern

- West Coast Main Line

(b) Midland Main Line

10. East Coast Main Line

(8) North Transpennine: Leeds-Manchester

( Great Western Main Line: Paddington-Reading

(1) West Midlands

Coventry-Wolverhampton

- Manchester hub

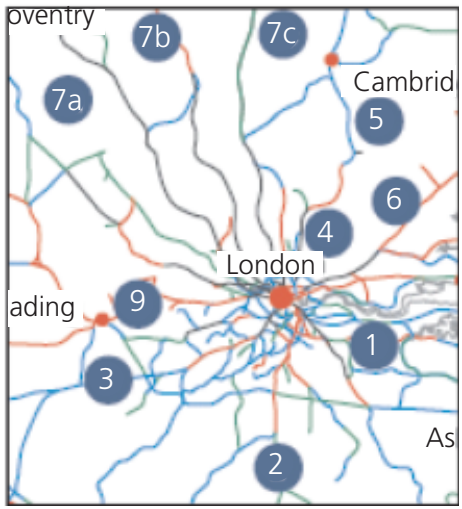

Figure 2. Summary route utilisation index for England and Wales (Network Rail, 2006a). The Capacity Utilisation Index is calculated from the existing services and running at minimum possible intervals. The percentage of time occupied by the services then gives the index, namely the time the track is currently occupied

incentives to provide additional stock in order to meet peak demand, given the annual leasing costs per vehicle incurred.

The critical parameter in terms of service operation though will come down to a few main issues that significantly impinge on capacity, train capacity, availability of train paths at key junctions and platform availability/track access to those platforms.

\subsection{Methods to enhance capacity}

In looking to expand the railway, seven methods of increasing capacity have been identified (DfT, 2004) and are listed here.

(a) Increase service frequency (run more trains).

(b) More efficient timetabling and reduction in station stop times.

(c) Pricing to shift passenger demand out of the peak into shoulder peaks.

(d) Reconfiguration of existing stock to optimise its use and capacity where required.

(e) Lengthening trains and platforms.
( $f$ ) Increase station capacity to handle larger volumes of passengers more quickly.

$(g)$ Elimination of pinch points on the railway and new lines.

Items $(a)$ to $(d)$ can be considered as softer and potentially cheaper operational changes within the existing infrastructure for potential quick implementation, making better use of existing resources. Items $(e)$ and $(f)$ are more medium-term options with potentially larger costs associated and finally $(g)$ is for longerterm strategic expansion and likely to be costly, but is increasingly becoming considered necessary. Each of these is considered briefly. (Item (c) has been covered above.)

\subsubsection{Increase service frequency}

Where the train service provision has traditionally been run on the basis of what was deemed commercially or financially sensible the infrastructure would not have been operating at capacity, but the service constrained by the availability of stock or crew. Therefore there is sufficient capacity within the system 
Transport

Volume 165 Issue TR3
UK rail transport: a review of demand

and supply

Ison, Frost and Watson to increase the frequency or the level of service provision to make use of the spare track capacity in many places (SRA, 2003).

It could be argued that this is what has happened over the decade since rail privatisation where the number of services running has increased as train operators have increased the number of trains running on many lines. However, the scope for further such improvements is becoming limited in key areas (Network Rail, 2006a). It is widely reported that there is a general shortage of suitable trains to run some services (although more trains are being ordered) and spare track capacity has been used up on many of the key routes that are suffering congestion, mainly within the south-east and on approach to the major UK rail hubs such as Manchester, Birmingham and approaches to London (Figure 2).

\subsubsection{More efficient timetabling and reduction in station stop times}

Following development of the route utilisation strategies many timetables have been recast to optimise the usage of trains, but also to increase reliability and in some areas lengthen journey times to provide such improvements (Network Rail, 2006b) However, this then starts to impinge on the operation of stock and the amount of stock available starts to limit capacity as stock is tied up for longer.

Although reducing station dwell/turnround times may seem simple this is frequently not achievable due to the large numbers of passengers wanting to access or egress particularly from crowded trains (although this may be helped by revised door layouts on new stock). At terminals this can be achieved by careful planning of the turnaround and the management of passengers; however, this may be constrained by signalling and station throat capacity or the efficient diagramming of stock and crews.

\subsubsection{Reconfiguration of existing stock to optimise its use and capacity}

This again can be considered a quick fix where existing stock is adjusted, moved or cascaded when new stock becomes available to provide extra services or longer trains where the infrastructure will allow. However, this can only occur where the train types available are suitable for the service type and pattern required, and where cooperation between train operators can be assured, to allow stock to be freed up within the privatised leasing arrangements. In addition some trains have had the internal carriage arrangements adjusted to increase seating provision or had seats and lavatories removed to provide extra standing passenger space to increase capacity (Network Rail, 2007a).

\subsubsection{Lengthening trains and platforms}

This is the first of the capacity changes that may require some additional infrastructure or modifications to existing infrastructure to accommodate longer trains. Although the provision of longer trains may in itself seem simple, there can be significant knock- on effects both to the trains and the infrastructure. However, on many routes, extending relatively short current two- or four-car trains and/or combining units to provide additional capacity is quite simple and can be easily done if stock is available and compatible.

However in some areas mainly the south-east and London, eight and 12 car trains are already common and to ease crowding on such services extension to 16 car trains has been investigated (Network Rail, 2007a). This is the main area where infrastructure works will be required if trains are already at platform length capacity, however issues with the trains themselves may cause problems.

Modern trains normally feature extensive onboard computer diagnostics and control and this may impact on the ease with which new carriages can be added. Often trains feature distributed power units along the train and this again can influence the links with the existing trains or their extension. This can present new maintenance problems in terms of increased costs, but potentially also for the maintenance infrastructure such as the size and through-put of depots and storage. Larger trains may still not fit platforms in some cases and may require selective door opening equipment which again may require reconfiguration of train management systems for all the stock.

For the infrastructure, the longer trains may simply require longer platforms but this may require acquisition of land for construction, reconfiguration/repositioning of track, signalling and electrification systems all to allow the platforms to be built. Extension of station facilities may also be required to accommodate additional through-put of passengers. Finally modification of power supplies due to increased power demand may also be needed in electrified areas.

Another option is to look at the provision of double-deck trains as used in mainland Europe; however, recent reports found that the comparatively small UK structure gauge makes a move to such trains expensive due to the need for regauging and route availability. Therefore longer trains are preferred for use on the existing infrastructure (Network Rail, 2007a).

\subsubsection{Increase station capacity}

In a number of areas the stations are incapable of handling increased passenger flows due to sizes of access, egress, over bridges or under passes to access platforms, etc., which again may have similar affects on the infrastructure as described above.

\subsubsection{Elimination of pinch points, addition of new lines and major enhancements}

This is the most significant of the capacity enhancements in terms of costs and extent of works. Perhaps the beneficial change within the existing network to increase capacity would be to modify or eliminate junctions where diverging/merging train moves close a number of running lines to through traffic. On the UK East Coast 
Main Line there are a number of prime examples where intersections such as grade crossings affect train capacity and works are being considered or are under way to remedy this (Network Rail, 2008, 2009b, 2009c). At Hitchin, where the line to Cambridge leaves the East Coast Main Line, the junction is considered to contribute 1800 delay minutes to services each year and its removal will add an extra 18 train paths. The removal of the Hitchin flat junction will be by means of a new flyover.

On main lines there are a number of places where a four-track railway drops to two tracks for relatively short lengths. These pinch points control the potential flow along the corridor, and also affect the speed of other trains operating in a mixed-use railway. During the West Coast route modernisation a two-track section of the route has been widened to four tracks over a 12 mile length in order to provide additional capacity (Network Rail, 2008).

The provision of such widening works and junction modifications is frequently extensive, and requires compulsory purchase of land that can take years due to protracted planning processes. Additionally they can not be undertaken in isolation as they may relieve one capacity constraint to focus problems on to the next.

In a number of areas of the network, as part of previous route rationalisation and cuts to reduce maintenance costs, tracks were removed to produce single lines with passing places or remove through lines at stations. On a number of routes, plans are being implemented to reinstate such additional tracks to increase capacity. Some single-track routes are being revised to increase lengths to twin track or provide more passing loops (Network Rail, 2007b). Such projects normally require works to rebuild station or platforms and structural works such as bridge strengthening, re-slewing of the single lines and re-signalling (as well as provision for electrification, if required).

On other routes, lengths are currently being returned from two-track operation to three lines and additional freight tracks, where present, are being reconstructed to increase line speeds to allow greater passenger train operational flexibility/reliability and capacity, as well as allow for maintenance diversions (Network Rail, 2006a).

\subsection{Signalling enhancements}

On some lines it is the signalling that limits the number of trains that can be run where signal section lengths have been extended under previous rationalisations or old signalling systems are still operational. Enhancing signals, adding additional signal sections, and making modifications to the existing systems can all enhance capacity by allowing more trains to run at closer headways. This is often undertaken with works to improve line speeds. In other areas modification of the signalling arrangements at junctions or changing junction layouts can help to increase junction operational times and hence line throughput.

On busier lines where four-aspect signalling currently exists it is hoped that modification to the new European Rail Traffic
Management System (ERTMS) incorporating in-cab signalling and potentially moving block to optimise the signalling systems will allow reductions in headways and hence increase traffic throughput. However, studies have shown that the potential benefits of this may be minimal, especially on high-speed lines. Additionally, in terms of capacity this will have limited influence on already congested lines, as other issues may be the main capacity constraints rather than the plain line track (Network Rail, 2009b).

\subsection{Major rebuilds or new lines}

Major upgrading of main lines has recently been undertaken on the West Coast Main Line. However, it has been suggested that the costs of rebuilding an operational railway are very high in terms of constraints on the engineering time and the consequent delays and knock-on effects to train services.

In January 2009 High Speed Two Ltd was established by the UK government with the remit of considering the new high-speed rail network options for Britain, the first being a new line between London and Birmingham. High Speed Two Ltd reported back to the government in December 2009 with detailed recommendations and a range of options based on a strong business case. The government view is that over the next 20 to 30 years a stepchange in transport capacity will be required with respect to serving the UKs largest and most productive urban areas and that this needs to be undertaken in a sustainable, environmentally friendly way. In this regard high-speed rail is viewed as the most effective way this can be achieved (DfT, 2010b).

A Y-shaped high-speed rail link, in the region of 335 miles, would seek to serve London to Birmingham, Manchester, the East Midlands, Sheffield and Leeds with an expected train speed of $250 \mathrm{mph}$. Connections to existing track would allow for direct links to Glasgow, Edinburgh, Newcastle and Liverpool. As well as providing additional capacity, the proposals would also free up the capacity of the existing network for both passenger and/or freight trains. Following formal public consultation in autumn 2010 and depending on parliamentary approval and timescales, construction of the high-speed rail link could commence in 2017 with phased opening from 2026.

\subsection{Electrification}

Wide-scale electrification of the rail network is being seriously discussed at present (DfT, 2009c). The primary drivers of this are sustainability and long-term security of energy supply. An increase in electrification would result in a decrease in the rail industry carbon footprint for the electrified routes of between 20 and $35 \%$ (Atkins, 2007).

Electrification does not in itself provide more capacity, although the need for physical works and new trains can be used as an opportunity to create more capacity through better acceleration characteristics, new signalling and the removal of bottlenecks in parallel with the electrification works. In addition, electrification 
Transport

Volume 165 Issue TR3
UK rail transport: a review of demand

and supply

Ison, Frost and Watson may help provide more capacity on routes with frequent stops, where higher acceleration enables more trains per hour to be handled over each section.

\subsection{Freight}

Freight trains tend to be longer and heavier and hence accelerate, brake and run more slowly than passenger trains. Within a mixed traffic railway this can present significant problems in optimising train paths, or delaying passenger traffic or reducing the other train paths available.

Furthermore, the passage of freight trains has a significant impact on the infrastructure. The movement of shipping containers can be limited to UK routes with appropriate gauge and load clearance. The weight of heavy bulk freight can have significant impact on the track condition, and an increased rate of deterioration of track quality. This in turn can have consequent maintenance delays and impacts to other traffic. Of course the "mix of speeds' issue also relates to passenger services, as well as the freight/passenger issue. For example, there is the conflict between running frequent local stopping services and also seeking capacity for non-stop services over the same section.

The provision of additional track capacity and gauge clearance of secondary routes can help resolve some of the mixed railway conflicts. However, main freight routes still involve crossing main lines and then the through-put at junctions again becomes an issue.

Possible options for increasing capacity for freight within the existing network include simply using longer trains; however, this can present issues with existing signal section and passing loop length, and depot facilities (in terms of loading capacity and train capacity). Studies have also looked into using lighter wagons to increase payload, and the use of higher axle loads or more axles to increase pay loads (which all have traffic loading implications), and finally running freight trains at higher speeds to integrate them more appropriately with passenger traffic (Network Rail, 2007b).

\subsection{Engineering access and track availability}

Over recent years there has been increasing disquiet among passengers and freight operators about the extensive time for which railway lines are shut for maintenance or that trains are replaced by buses (Network Rail, 2007c).

Prior to railway privatisation a large proportion of maintenance was undertaken with overnight possessions and single line working, plus, with flexibility of use of stock under one operator, diversionary routes were potentially more usable. In addition, the safety regime of the railway has changed and this has in many cases precluded the use of works on the live railway. This has meant that most railway works are now undertaken using a full track possession and during maintenance the train services are replaced by buses, which tend to be unpopular with passengers.

Freight operators have also complained about loss of access, for maintenance, to run regular freight services particularly on gauge critical routes.

Network Rail has been instructed by the ORR to move towards a 'seven day' railway, with engineering works to be carried out during $8 \mathrm{~h}$ possessions, reducing the number of major blockades, and provide appropriate diversions. This requires amendments to the network to provide more resilience in the systems and increased diversionary possibilities.

The cost of carrying out engineering works during $8 \mathrm{~h}$ possessions is potentially greater than under blockades. Therefore, changes in the way engineering works are carried out and the move to automation and high-output maintenance plant are being taken forward. It terms of infrastructure, the move is now towards offsite modular construction with simple interfaces for the installation of signalling, telecommunications, level crossings, switch and crossing works and some structural works.

\section{Conclusions}

The structure of the UK railway that was developed for privatisation created a number of issues, particularly related to how to accommodate growth, the level of which has, since privatisation, been significantly higher than any government or independent predictions. The subsequent revisions to railway organisations and responsibilities have created a structure in which the UK government sets the strategy and provides much of the funding for investment with the private sector taking responsibility for delivering the service.

The government sets the high level policy deliverables for the rail industry and what it expects the railway to achieve via an HLOS. It also controls how this is to be delivered via a SOFA. The rail industry is expected to deliver the railway anticipated for the money available and as part of the process of agreeing the HLOS and SOFA an appraisal of different expenditure options is undertaken to enable the government to ensure that it achieves 'best value' for the taxpayers' money that it spends on railways.

Over recent years the rail industry has seen a large growth in passenger numbers and freight usage, which has been caused by many contributing factors. This has placed increased demand on a network which in some areas is running at or over capacity with little scope for accommodating future growth without investment.

Areas where such capacity is or will be limited have been identified via the development of route utilisation strategies. The principles of the methods for how extra capacity can be provided or enhanced or alternatively the demand managed or met in an economic and viable way have been developed through this policy and areas of work identified.

The prospects for further growth in volumes of passengers and freight transported by rail are good, subject to the overall economic climate and receiving adequate funding from govern- 
Transport

Volume 165 Issue TR3
UK rail transport: a review of demand

and supply

Ison, Frost and Watson ment, with there being general acceptance that this will continue to be required to get 'best value' from the railway. As increasing railway usage is seen as a key way of helping meet the UK's sustainability targets for transport it is not anticipated that funding will be significantly reduced, although the overall pressure on government finances is likely to lead to some slippage in the time when investment is delivered and hence rates of growth.

\section{Acknowledgement}

The authors would like to thank CIRIA and the UK Modern Build Environment Knowledge Transfer Network (KTN) for funding the support work that contributed to this paper, in particular Philip Charles and Brian Bell. However, the views expressed are those of the authors and not of the KTN.

\section{REFERENCES}

Atkins (2007) T633: Study on Further Electrification of Britain's

Railway Network. Railway Safety and Standards Board,

London, UK.

DfT (Department for Transport) (2004) The Future of Rail. The Stationery Office, London, UK, White Paper CM 6233.

DfT (2007a) The NATA Refresh: Reviewing the New Approach to Appraisal. DfT, London, UK. See http://

webarchive.nationalarchives.gov.uk/+/http://www.dft.gov.uk/ consultations/open/consulnatarefresh/pdfnatarefresh.pdf (accessed 18/08/2011).

Dft (2007b) Delivering a Sustainable Railway. The Stationery Office, London, UK, White Paper CM 7176.

DfT (2008) Transport Statistics Great Britain 2008. The Stationery Office, London, UK.

DfT (2009a) About the DfT Rail Group. DfT, London, UK. See http://www2.dft.gov.uk/pgr/rail/rail/(accessed 18/08/2011).

DfT (2009b) NATA Refresh: Appraisal for a Sustainable Transport System. DfT, London, UK. See http://

www.bettertransport.org.uk/system/files/ DfT_NATA_refresh2009.pdf (accessed 18/08/2011).

DfT (2009c) Britain's Transport Infrastructure: Rail Electrification. DfT, London, UK.
DfT (2010a) Spending Review. DfT, London, UK. See http:// www2.dft.gov.uk/about/spendingreview.html (accessed 18/08/ 2011).

DfT (2010b) High Speed Rail Summary. DfT, London, UK.

Goodwin P (2004) The Economic Costs of Road Traffic Congestion - Discussion Paper. The Rail Freight Group, London, UK.

House of Commons Public Accounts Committee (2009) The Department for Transport: Letting Rail Franchises 2005 2007, Twenty-first Report of Session 2008-09. The Stationery Office, London, UK, HC 191. See http:// www.publications.parliament.uk/pa/cm200809/cmselect/ cmpubacc/191/191.pdf (accessed 18/08/2011).

ORR (Office of Rail Regulator) (2009) Rail performance. In National Rail Trends. ORR, London, UK, chapter 2.

Network Rail (2006a) Network Rail Business Plan. Network Rail, London, UK.

Network Rail (2006b) Route Utilisation Strategy (RUS) South West Main Line. Network Rail, London, UK.

Network Rail (2007a) Network Rail 2007 Preliminary Evaluation of Double Deck and Extra Long Train Operations. Network Rail, London, UK.

Network Rail (2007b) Freight, Network Rail Utilisation Strategy. Network Rail, London, UK.

Network Rail (2007c) The Seven Day Railway, Network Rail Strategic Business Plan (Supporting Documents). Network Rail, London, UK.

Network Rail (2008) Route Utilisation Strategy (RUS) East Coast Main Line. Network Rail, London, UK.

Network Rail (2009a) Network RUS: Scenarios and Long Distance Forecasts, Draft for Consultation. Network Rail, London, UK.

Network Rail (2009b) Network Rail, Control Period Four Delivery Plan 2009. Network Rail, London UK.

Network Rail (2009c) Network Route, Utilisation Strategy. Network Rail, London, UK.

SRA (Strategic Rail Authority) (2003) Capacity Utilisation Policy (Network Utilisation Strategy). SRA, London, UK.

\section{WHAT DO YOU THINK?}

To discuss this paper, please email up to 500 words to the editor at journals@ice.org.uk. Your contribution will be forwarded to the author(s) for a reply and, if considered appropriate by the editorial panel, will be published as a discussion in a future issue of the journal.

Proceedings journals rely entirely on contributions sent in by civil engineering professionals, academics and students. Papers should be 2000-5000 words long (briefing papers should be 1000-2000 words long), with adequate illustrations and references. You can submit your paper online via www.icevirtuallibrary.com/content/journals, where you will also find detailed author guidelines. 